\title{
Improvement in Construction Planning Effort by Small and Medium Enterprises (SME) in the UK over the last 12 years
}

\author{
Mohammadullah H Ebrahimi ${ }^{1}$ and Kassim Gidado ${ }^{2}$
}

\begin{abstract}
Planning provides the roadmap for successful project delivery. In the UK construction industry appropriate planning and programming of construction projects is considered one of the critical factors in determining project success. However, research has shown that the construction industry does not focus enough on planning and programming practices, resulting in an increase of projects delays and exceeding budgets.

In 1998 a research conducted by Bigelow (Bigelow, 1998) on why we do not do more planning identified factors such as time and cost constraints, lack of planning knowledge, changes to the original project plan, an existing culture that does not understand the value of planning and customers who do not know what they want. This research has taken the same factors and asked practitioners to respond on why they do not do more planning. The findings suggest that in the last 12 years there has been no significant improvement in attitudes towards planning in SMEs in the UK construction industry. The research carried out is based on a desk study and the use of questionnaires sent to a selection of a $100 \mathrm{SME}$ construction companies.
\end{abstract}

Keywords: construction planning, construction programming, success factors, SMEs,

\section{Introduction}

The completion of any construction project in Time and within Cost and to the intended Quality requires effective use of planning systems. Moreover, to plan a project effectively, planning tools and techniques (T\&T) are essential. However, in the last 12 years there has been no significant improvement in attitudes towards planning in SMEs in the UK construction industry. This paper will provide general information on the use and importance of planning and then the research methodology and data collection method used for this paper. Then, the finding of the research and recommendation for further studying on the use and importance of planning in the construction industry will be discussed.

\footnotetext{
${ }^{1}$ Faculty of Construction, Kabul Polytechnic University, Kabul-Afghanistan

${ }^{2}$ School of Environment \& Technology, University of Brighton, Brighton, BN2 4GJ, UK
} 


\section{Background}

Various literatures and texts confirm that right planning at the right time for a construction project is very essential. Scholars believe that projects such as the Egyptian Pyramids and Great Wall of China will never have been constructed without project planning and management (Burk, 2006). He argues that although there is no documented evidence of the management processes, they were certainly large and complex structures, which were built to high standards. Planning is a way of thinking ahead and it needs effective T\&T, as Burk (2006, p. 94) states "planning asks questions, encourages participation, creates awareness, prompts actions, solve problems, and formalises decisions based on consensus" but it is important to consider and apply the right planning T\&T effectively. Different types of planning $T \& T$ can be considered according to the type, size, duration and complexity of the construction project or as a matter of personnel preferences or through an agreement in the contract.

Moreover, successful and effective planning and control of construction projects require logical methods and techniques in order to ensure a successful outcome for the client, contractors and other participants (Cooke and Williams, 2009). Without planning projects, it is hard to imagine effective control of time, money and dealing with risks, so a successful conclusion of any project depends on effective planning.

The main aim of planning is to programme all activities for a project according to the time available for each and as Gidado $(1989$, p. 1) states planning is "to complete the contract in the shortest possible time compatible with the economy". However, in practice, a large number of construction projects fail to meet their original time and cost targets. For example, a report by the National Audit Office in 2001, (NAO, 2001) has revealed inefficiencies in traditional methods of procuring and managing construction projects and, particularly, when contracts awarded based on lowest price. According to the report $70 \%$ of projects that were carried out by government departments and agencies were delivered late and $73 \%$ were over budget. The report further revealed that of $66 \%$ of central government construction projects (total value $=£ 500$ millions) carried out in $1999,75 \%$ were over budget by up to $50 \%$, and $63 \%$ exceeded their original time.

However, in practice, we tend to do very little planning. In 1998 a study carried out by Bigelow, (Bigelow, 1998) the title of which is (Planning is important why don't we do more of it?) indicated that lack of planning in construction projects is the most significant cause of failure for many projects. She further states, we tend to get nervous because it takes too much time or gets too detailed to plan a project and, also because we cannot see a quick result of our planning, therefore we develop project schedule without a realistic estimates of time, cost, etc. She argues that too often senior management who are responsible for projects used to produce a Gantt chart in project management software and believes it is a project plan; while it is nothing more than just an "arts and charts". Therefore, (Bigelow, 1998, p.1) believes one should not travel on a journey to unknown lands unless he/she has a direction map and, "planning - the most important yet most undervalued element of project management is the map that sets the direction for a project".

\section{Planning Stages}

According to Cooke and Williams (2009) in construction planning is usually divided into three main stages including: pre-tender planning, pre-contract planning and contract planning. According to Cooke and Williams each stage is briefly discussed below: 
1- Pr-tender planning - a pre-tender planning is usually prepared by contractors and shows their consideration; it is used as an aid to tendering process. The pre-tender programme further helps the estimator to estimate the method related items and also time-related costs.

2- Pre-contract planning - based on traditional procurement the winner contractor develop pretender programme into contract master programme and shows all the main activity init.

3- Contract planning - contract planning is prepared by the main contractor to maintain and ensure that the work is done on-time within budget limits. It is mainly the breakdown of the master programme into stage, short term and weekly programme.

However, the intention of this study is the pre-contract stage. At this stage, more information is available about any construction project and planners/schedulers can plan, and programme the activities accurately.

\section{Research Methodology}

Data has been obtained through two primary avenues a desk study and questionnaire. Questionnaires were sent out to a selection of 100 Small to Medium sized (SME) construction companies, in the UK. Before sending out the questionnaires a pilot study (test study) was launched within the University of Brighton and the questions were discussed with the academic staff at the School of Environment and Technology. The main reason for a pilot study was to verify whether the questions were highly relevant to the objectives of the study. Feedback from the pilot study suggested that some of the questions were not politically correct; some appeared misleading and may have been perceived as intrusive or different from what was intended. For instance, some questions were ambiguous and needed to be rephrased and some would have created duplicity. Some questions were removed or rephrased following feedback from the pilot study with regard to their applicability to the study.

\section{Data Collection}

The data collection method applied to the study was survey through questionnaire. The questionnaires were conducted mainly to capture practical views and opinions of practitioners in the construction industry on programming and planning practice with particular reference to the pre-contract stage of SMEs construction projects. A cold approach was used, and delegates were asked to reply within three weeks of receipt however, three weeks deadline was extended to four because enough responses were not collected during the intended data collection period.

Developed questionnaires, accompanied by a cover letter, were sent out to a $100 \mathrm{SME}$ construction companies, project management and planning consultancies and individual experienced planners in the UK. Most of the individual planners were either members of Planning Planet or personal networks of the author or author's friends. Planning Planet is a planning website which has thousands of members worldwide; however the questionnaires were sent to the UK members only (Planning Planet FUROM, 2010). Figure 5.1 indicates the position of the respondents and their percentages. During the pilot study it was suggested that to maximise numbers of responses, the questionnaire should be developed 
and sent both as an on-line survey and also in Microsoft Word format because some companies internal procedures do not allow their staff access some specific websites. The on-line survey was developed in Kwik Surveys, a free online survey tool. Of the 100 questionnaires sent, 29 were returned completed within the stipulated four week time, giving a response rate of $29 \%$.

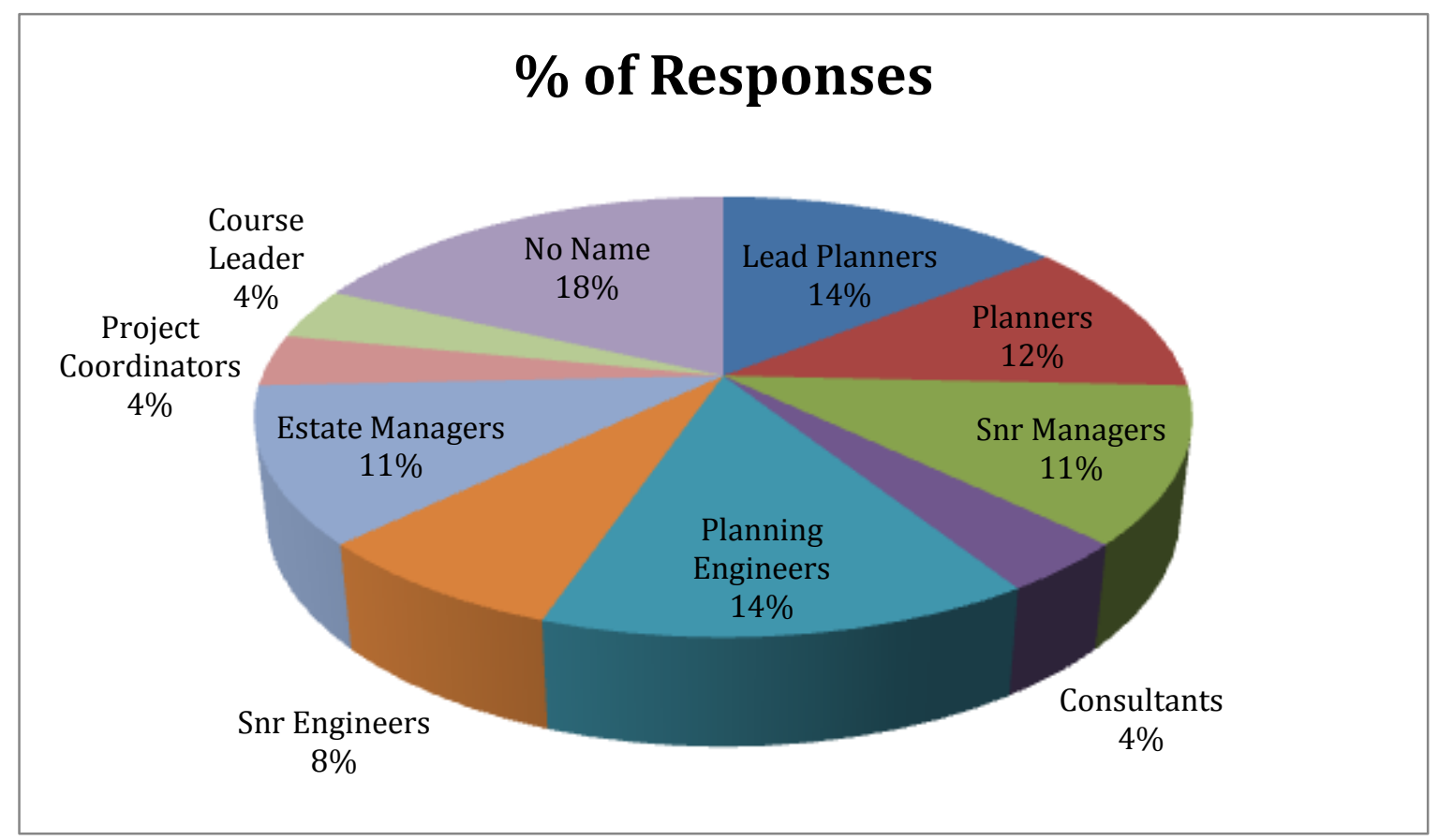

Figure 1. Graphical Representations of the respondents

Of the $29 \%$ returned questionnaires represented in the pie chart, 2 were not useable, 1 was duplicated and other 2 answered only one or two questions. Therefore, 24 of the questionnaires had positive and reliable responses; hence, analysis of the data is based on the 24 responses. As can be seen from Figure 5.1, more than 33\% of the respondents are senior Planners, Managers and Engineers, and $40 \%$ are planners, which can grantee the significant and reliability of the data.

\section{Aim and objectives of the Survey}

The survey aims to:

- Find out whether the statements made by Bigelow in 1998 are still a reason (s) for not doing more planning, in the UK construction industry.

\section{Objectives:}

- To investigate why in the UK construction industry most of the SMEs do not do more planning;

- To ascertain the needs for further research into planning construction projects. 


\section{Data Analysis}

Date was analysed using an important index with a likert scale of 'Strongly agree', 'Agree', 'Nutral', 'Disagree' and 'Stronlgy disagree' (figure 2). Basically the respondents were asked to give a weighting for the following reasons that might hinder greater use of planning at the pre-contract stage.

\begin{tabular}{|c|c|c|c|c|c|c|c|c|}
\hline Statements/reason & Rank & $\begin{array}{l}\text { Strongly } \\
\text { agree } 4\end{array}$ & Agree 3 & $\begin{array}{l}\text { Neutral } \\
2\end{array}$ & $\begin{array}{l}\text { Disagree } \\
1\end{array}$ & $\begin{array}{l}\text { Strodly } \\
\text { desagree } 0\end{array}$ & $\begin{array}{l}\text { Important } \\
\text { Index }\end{array}$ & Rank \\
\hline It takes too much time & 1 & 7 & 7 & 6 & 1 & 2 & 2.6 & 1 \\
\hline $\begin{array}{l}\text { The cost is fairly } \\
\text { expensive }\end{array}$ & 2 & 4 & 6 & 7 & 3 & 3 & 2.1 & 6 \\
\hline Lack of IT facility & 3 & 3 & 5 & 9 & 3 & 3 & 2 & 2 \\
\hline Lack of clear benefit & 4 & 4 & 6 & 3 & 6 & 4 & 1.9 & 10 \\
\hline Don't know how & 5 & 3 & 4 & 6 & 6 & 3 & 1.75 & 7 \\
\hline $\begin{array}{l}\text { Existing culture } \\
\text { doesn't see the value }\end{array}$ & 6 & 5 & 7 & 8 & 2 & 2 & 2.4 & 3 \\
\hline $\begin{array}{l}\text { The plan will change } \\
\text { later on }\end{array}$ & 7 & 3 & 5 & 8 & 6 & 1 & 2 & 4 \\
\hline $\begin{array}{l}\text { Customer doesn't } \\
\text { know what they want }\end{array}$ & 8 & 3 & 4 & 8 & 5 & 3 & 1.9 & 8 \\
\hline $\begin{array}{l}\text { Don't want to commit } \\
\text { and be held } \\
\text { accountable }\end{array}$ & 9 & 2 & 1 & 11 & 6 & 3 & 1.6 & 5 \\
\hline $\begin{array}{l}\text { Lack of human } \\
\text { resources }\end{array}$ & 10 & 3 & 5 & 11 & 2 & 2 & 2.1 & 9 \\
\hline Other please indicate & & & & & & & & \\
\hline
\end{tabular}

Table 1. Results from the survey on, why we do not do more planning at the pre- 


\section{Discussion of findings}

In order to differentiate between positive and negative answers i.e. (agrees and disagrees), neutral column is considered as the central line between the two. Therefore, any statement in the table gets 8 or more than 8 answers (agree and strongly agree) means that more than $50 \%$ of the respondents agreed on it and conversely any statement get less than 8 answers (disagree and strongly disagree) means that less than $50 \%$ agreed on it.

1. Based on the important index analysis, it can be summarised that if any of the above ten reasons have a score of above 2.5 , the respondents strongly agreed with that; if it has a score between 2-2.5, the respondent agreed with that reason. If the important index score was between 1.5-2 it is a neutral reason for the respondents, whilst a score of less than 1.5 could be considered as a disagreed or strongly disagreed reason for not doing more planning at the pre-contract stage.

2. As can shown in the table, with the statement "it takes too much time", 7 respondents 'strongly agreed', 7 'agreed', while only 3 disagreed' or strongly disagreed. The result indicates that 14 out of 24 respondents agree on they do not do more planning because "it takes too much time".

3. With the statements "the cost is fairly expensive" 10 respondents agree and only 6 were not agreeing.

4. Similarly for the statements such as "existing culture does not see the value", "the plan will change anyway" and lack of human resources 12,8 and 8 respondents agreed respectively and less than $50 \%$ of the respondents or $(4,7$ and 4$)$ respondents disagreed.

5. Interestingly for the statement "lake of clear benefits" for the planning $50 \%$ agreed and 50\% disagreed. The judgment for this statement is difficult because half of the respondent agreed and half disagreed. However, the result suggests that still half of the construction companies do not know a clear benefit of planning and programming construction projects.

6. The results suggest that most of the reasons given in the above table are still issues in many construction companies for not doing more planning at the pre-contract stage and only a few respondents disagreed. Now it can be said that the results from this study improves the argument of Bigelow which was made in 1998. However, the statements such as "Don't know how", "Customer doesn't know what they want" and "Don't want to commit and be held accountable" are not any more a big issue to hinder the use of planning, and it is because now technology has developed and much more user friendly software packages are available, in the market. Also, nowadays, clients really know what they want to build. As can be seen from the table, more than half of the respondents do not believe that clients do not know what they want because by using Visual Architecture, 3D modelling and many other user friendly softwares clients can see their projects even before construction works start. Moreover, the results in the table further indicates a significant change about the statements "Don't want to commit and be held accountable" because only 3 respondents agreed while 9 disagreed. 


\section{Important index analysis}

very important $>$ important $>$ neutral $>$ unimportant

The different between the two assumed 1.1

Important index calculated from the following formula:

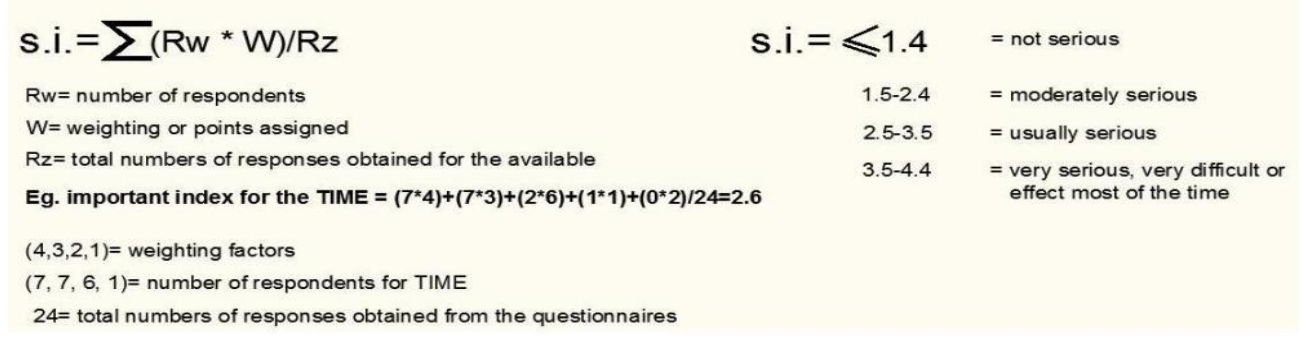

Figure 2. Important Index Analysis Formula

\section{Limitation of the Research}

Perhaps the short time scale of the research project was the biggest limitation of the study. For instance, some of them replied just a few days before the deadline of research project, and these were not used for this study. Nevertheless, the reluctance of practitioners within the construction industry to participate in the survey was another limitation in carrying out this research. If this had not been the case, in addition to the questionnaire survey, the author would have been able to interview some construction planners with the aim of knowing why they do not plan their construction projects.

\section{Conclusion}

The results from this study suggest that over the last 12 years there has not been a significant change in the attitudes of construction SMEs toward planning projects. More than $50 \%$ of the respondents participated in the survey agreed that factors such as "it takes time to plan a project, 'The cost is fairly expensive', 'Existing culture doesn't see the value', 'The plan will change anyway' and 'Lack of human resources' are still issues which prevent them from doing more planning at the pre-contract stage. Also the results showed some improvement on the argument of Bigelow which was made in 1998. However, the study indicated that factors such as 'Customer doesn't know what they want', 'Don't know how', Don't want to commit and be held accountable' which were issues 12 years ago are not now an issue. Further research should be carried out, preferably by interviewing planners, to find out why construction companies do not do more planning, although they know about the benefits of planning. 


\section{References}

- Burk, R., 2006. Project management: planning and control techniques. $4^{\text {th }}$ ed. England: John Wiley \& Sons.

- Cooke, B. and Williams, P., 2009. Construction planning, programming and control. 3rd ed. UK: Blackwell.

- Deborah, B., 1998. Planning Is Important-Why Don't We Do More Of It? MIDDLE GROUND, PM Network 12 (7), 15-16.

- Gidado, K., 1989. Construction planning and programming techniques. UK: University of Brighton.

- Kwik Surveys, 2010. Free ultimate surveys. Available from: http://www.kwiksurveys.com/ [Accessed 7 July 2010].

- National Audit Office, 2001. Modernising construction. Report by the Comptroller and Auditor General HC 87. The stationary office.

- Planning Planet Team, 2010. Networking, planning, scheduling and management controls professionals, FUROM [on-line]. Available from: http://www.planningplanet.com/partners/index.php?q=team [Accessed 10 August 2010]. 